\title{
Highly efficient organic solar cells enabled by a porous ZnO/PEIE electron transport layer with enhanced light trapping
}

\author{
Shenya $\mathrm{Qu}^{1,2}$, Jiangsheng $\mathrm{Yu}^{1 *}$, Jinru $\mathrm{Cao}^{2}$, Xin $\mathrm{Liu}^{1}$, Hongtao Wang ${ }^{1,2}$, Shun Guang ${ }^{1,2}$ and \\ Weihua Tang ${ }^{2 *}$
}

\begin{abstract}
In this study, a porous inorganic/organic $(\mathrm{ZnO} /$ PEIE, where PEIE is polyethylenimine ethoxylated) ( $\mathrm{P}-\mathrm{ZnO})$ hybrid material has been developed and adopted in the inverted organic solar cells (OSCs). The P-ZnO serving as the electron transport layer (ETL) not only presents an ameliorative work function, but also forms the cratered surface with increased ohmic contact area, revealing suppressed charge recombination and enhanced charge extraction in devices. Particularly, P-ZnO-based OSCs show improved light trapping in the active layer compared with $\mathrm{ZnO}$-based ones. The universality of $\mathrm{P}-\mathrm{ZnO}$ serving as ETL for efficient OSCs is verified on three photovoltaic systems of PBDB-T/DTPPSe2F, PM6/Y6, and PTB7-Th/PC ${ }_{71}$ BM. The enhancements of $8 \%$ in power conversion efficiency (PCE) can be achieved in the state-of-the-art OSCs based on PBDB-T/DTPPSe-2F, PM6/Y6, and PTB7-Th/PC $\mathrm{PC}_{71} \mathrm{BM}$, delivering PCEs of $14.78 \%, 16.57 \%$, and $9.85 \%$, respectively. Furthermore, a promising PCE of $14.13 \%$ under air-processed condition can be achieved for $P$ $\mathrm{ZnO} / \mathrm{PBDB}-\mathrm{T} / \mathrm{DTPPSe}-2 \mathrm{~F}-\mathrm{b}$ ased OSC, which is among the highest efficiencies reported for air-processed OSCs in the literature. And the P-ZnO/PBDB-T/DTPPSe-2F-based device also presents superior long-term storage stability whether in nitrogen or ambient air-condition without encapsulation, which can maintain over $85 \%$ of its initial efficiency. Our results demonstrate the great potential of the porous hybrid $\mathbf{P}$ $\mathrm{ZnO}$ as ETL for constructing high-performance and air-stable OSCs.
\end{abstract}

Keywords: light trapping, electron transport layer, porous structure, stability, organic solar cells

\section{INTRODUCTION}

Organic solar cells (OSCs), as one of emerging photo- voltaic technologies, have attracted enormous attention in view of their unique merits, such as semi-transparency, solution processability and mechanical flexibility [1-5]. A high power conversion efficiency (PCE) over $18 \%$ has been realized in single-junction OSCs due to the rapid progress associated with semiconducting materials and device innovations [6-9]. In view of photoactive material aspects, polymers or small molecules have been intensively investigated and developed along with the combination of binary or multicomponent donor/acceptor materials [10-19], and optimal nanoscale morphology of bulk-heterojunction (BHJ) active layers [2024]. In the sandwiched device architectures, engineering and optimization of the interfaces between photoactive layer and metal electrodes are also crucial and challenging, which can promote the photogenerated charge carrier collection.

In the inverted devices, interfacial engineering of electron transport layers (ETLs) is widely exploited to implement high-performance OSCs [25-27]. Besides the principle of energy alignment between the photoactive layer and metal electrode, the high transparency and mobility of ETLs are also accounted [28-30]. Up to now, metal oxides such as zinc oxide $(\mathrm{ZnO})$ and titanium oxide $\left(\mathrm{TiO}_{2}\right)$ are frequently served as ETLs to form ohmic contact for facilitating charge transport and collection $[31,32]$. The primary selective sol-gel $\mathrm{ZnO}$ is utilized in numerous efficient OSCs due to its high electron mobility $\left(\sim 5 \mathrm{~cm}^{2} \mathrm{~V}^{-1} \mathrm{~s}^{-1}\right)$ and superior optoelectronic properties [33]. However, the intrinsic defects and charge traps always accompany each other at the surface and bulk of $\mathrm{ZnO}$ film depending on the thermal annealing process, which could lead to severe charge recombination [34]. To

\footnotetext{
${ }^{1}$ MIIT Key Laboratory of Advanced Solid Laser, Nanjing University of Science and Technology, Nanjing 210094, China

${ }^{2}$ School of Chemical Engineering, Nanjing University of Science and Technology, Nanjing 210094, China

* Corresponding authors (emails: yjs@njust.edu.cn (Yu J); whtang@njust.edu.cn (Tang W))
} 
address these issues, many groups have been engaged to develop organic ETL materials for OSCs [35]. Recently, Lin et al [36] have explored glucose-based biopolymers as zinc oxide surface modifiers for the inverted OSCs, and the methyl-cellulose-modified $\mathrm{ZnO}$ ETL can enable improved performance in devices. Pan et al. [37] have reported an $\mathrm{N}$-doped ( $\mathrm{N}, \mathrm{N}$-dimethyl-ammonium $\mathrm{N}$-oxide) propyl perylene diimide-graphene (PDINO-G) as ETL through dispersing graphene in the alcohol-soluble PDINO, revealing the enhanced photovoltaic performance in several derived OSCs. Zhang et al. [38] have developed a novel interfacial cathode material, named as poly[ $(9,9$-bis (3'-( $N, N$-dimethylamino)propyl)-2,7-fluorene)-alt-5,5'bis (2,2'-thiophene)-2,6-naphthalene-1,4,5,8-tetracaboxylic- $N, N^{\prime}$-di(2-ethylhexyl)imide] (PNDIT-F3N). The derived homojunction tandem OSCs have exhibited remarkable stability with efficiency retaining $93 \%$ of their initial value after thermally aging at $80^{\circ} \mathrm{C}$ for $1000 \mathrm{~h}$.

To refine the interfacial contact of inorganic ETL, surface modifiers such as polyethylenimine (PEI) [39], PEI ethoxylated (PEIE) [40], and poly[(9,9-bis ( $3^{\prime}-(N, N-$ diethylamino)propyl)-fluorene)-alt-2,7-(9,9-dioctylfluorene)] (PFN) [41] have also been exploited. Benefiting from the reduced work function and better compatibility of the optimized ETL, the relative OSCs reveal suppressed charge recombination with boosted overall photovoltaic performance. However, there is a fatal drawback, that is, these polar materials have inherently low electrical conductivity and thus are extremely sensitive to thickness $[42,43]$. For the high-throughput solution-coating process of OSCs, there is a delicate balance to select organic or inorganic interface materials. Considering the above trade-offs, developing the promising interface material with suitable work function and superior conductivity is still highly desired for efficient and stable OSCs.

In this study, an organic/inorganic hybrid ETL with porous structure $(\mathrm{P}-\mathrm{ZnO})$ has been successfully adopted in the inverted OSCs, which is composed of PEIE and $\mathrm{ZnO}$. Herein, the PEIE was well dispersed in the $\mathrm{ZnO}$ precursor solution, and the spin-coated $\mathrm{P}-\mathrm{ZnO}$ films were processed with thermal annealing for forming $\mathrm{ZnO}$ crystal, solvent washing for porous structure, and heating for cleaning in sequence. The P-ZnO serving as ETL not only presented an ameliorative energy alignment between the photoactive layer and cathode (indium tin oxide (ITO)), but also formed a unique surface with increased ohmic contact area. Three active layer composites, PBDBT/DTPPSe-2F, PTB7-Th/PC ${ }_{71}$ BM and PM6/Y6 were utilized to explore the efficacy of P-ZnO as ETL. Consequently, compared with $\mathrm{ZnO}$-based counterparts, $\mathrm{P}-\mathrm{ZnO}$ - based OSCs revealed enhanced photovoltaic performance with improved short-circuit current density $\left(J_{\mathrm{SC}}\right)$ and fill factor (FF), which accounted for the suppressed charge recombination and enhanced charge extraction. Besides, the P-ZnO-based devices also showed improved light trapping in the active layer due to the softened reflection at the interface. High PCEs of $14.78 \%, 9.85 \%$, and $16.57 \%$ for devices based on PBDB-T/DTPPSe-2F, PTB7-Th/ $\mathrm{PC}_{71} \mathrm{BM}$ and $\mathrm{PM} 6 / \mathrm{Y} 6$ can be realized, respectively. Moreover, the devices based on P-ZnO/PBDB-T/ DTPPSe-2F exhibited distinguished fabricating flexibility whether in the nitrogen $\left(\mathrm{N}_{2}\right)$ or ambient air condition, delivering comparative photovoltaic efficiencies and satisfactory long-term storage stabilities. A decent PCE of $14.13 \%$ for air-processed OSCs was achieved, which is among the highest efficiencies reported for air-processed OSCs in the literature.

\section{EXPERIENTAL SECTION}

\section{Porous ETL preparation}

The $\mathrm{ZnO}$ precursor solution was prepared by dissolving zinc acetate dihydrate $\left(\mathrm{Zn}\left(\mathrm{CH}_{3} \mathrm{COO}\right)_{2} \cdot 2 \mathrm{H}_{2} \mathrm{O}\right.$, Aldrich, $1 \mathrm{~g}$ ) and ethanolamine (Aldrich, $0.14 \mathrm{~mL}$ ) in 2-methoxyethanol (ME, Aldrich, $5 \mathrm{~mL}$ ). The precursor solution was stirred overnight to yield a transparent solution. The $35 \mathrm{wt} \%$ PEI aqueous solution (PEIE, $80 \%$ ethoxylated, $M_{\mathrm{w}}$ $\sim 70,000 \mathrm{~g} \mathrm{~mol}^{-1}$, Aldrich) was diluted to $0.5 \%$ with $\mathrm{ME}$ and stirred overnight. Then $\mathrm{ZnO}$ precursor and dilute PEIE solutions were mixed with different volume ratios. The derived ETL films were spin-coated with the mixed solution at $5000 \mathrm{r} \mathrm{min}^{-1}$ for $30 \mathrm{~s}$ and annealed at $150{ }^{\circ} \mathrm{C}$ for $30 \mathrm{~min}$. Then the films were rinsed with $\mathrm{ME}$ at $3000 \mathrm{r} \mathrm{min}^{-1}$ for $30 \mathrm{~s}$ to form P-ZnO films, and heated for 10 min subsequently.

\section{Device fabrication}

All OSCs were fabricated with the inverted structure of ITO/ETL/active layer $/ \mathrm{MoO}_{3} / \mathrm{Ag}$. ITO/glass substrates with a sheet resistance of $15 \Omega \mathrm{sq}^{-1}$ were ultrasonically cleaned with detergent, deionized water, acetone, and isopropanol for $15 \mathrm{~min}$ each, and subjected with oxygen plasma for $180 \mathrm{~s}$ for further cleaning. The pristine $\mathrm{ZnO}$ films were spin-coated with the $\mathrm{ZnO}$ precursor solution, which contained dissolved zinc acetate dihydrate $(1 \mathrm{~g})$ and ethanolamine $(0.28 \mathrm{~mL})$ in $\mathrm{ME}(10 \mathrm{~mL})$. The $\mathrm{ZnO} /$ PEIE and P-ZnO films were spin-coated with the prepared mixed solution at $5000 \mathrm{r} \mathrm{min}^{-1}$ for $30 \mathrm{~s}$, respectively. The $\mathrm{BHJ}$ blend films were processed as previously reported [44-46]. The $\mathrm{MoO}_{3}(8 \mathrm{~nm})$ and $\mathrm{Ag}(150 \mathrm{~nm})$ 
layers were successively deposited by thermal evaporation.

\section{Characterization and device measurements}

The current density-voltage $(J-V)$ characteristics of all devices were measured under AM $1.5 \mathrm{G}$ at $100 \mathrm{~mW} \mathrm{~cm}^{-2}$ irradiance (Oriel $300 \mathrm{~W}$ Solar Simulator) with a Keithley 2400 Unit. The light intensity was calibrated with a standard silicon diode (KG5 filter). The typical active area was $3.97 \mathrm{~mm}^{2}$ as defined by a metal mask with an aperture. External quantum eciency (EQE) measurements were carried out from a Solar Cell Spectral Response Measurement System QE-R3011 (Enlitech Co., Ltd.) equipped with a standard Si diode. The film thicknesses were measured using Bruker Dektak XT stylus profiling system. The X-ray photoelectron spectroscopy (XPS) measurements were conducted using Thermo Scientific ESCALAB 250Xi spectrometer. The ultraviolent photoelectron spectroscopy (UPS) measurements were collected on a Thermo Fisher Scientific Ultra Spectrometer (ESCALAB 250Xi) He (I) $(21.22 \mathrm{eV})$ radiation line from a discharge lamp. All measurements were performed at room temperature $(296 \mathrm{~K})$. The contact angle measure- ments of derived films were performed on SL200C optical contact angle meter (Solon Information Technology Co., Ltd.).

\section{RESULTS AND DISCUSSION}

\section{Morphology characterization}

To manufacture the $\mathrm{P}-\mathrm{ZnO}$ films, a certain concentration of PEIE in ME was added to the $\mathrm{ZnO}$ precursor solution with a volume ratio of 1:2. After spin-coating with the prepared solution and thermal annealing, ME was utilized again to scour off PEIE component for forming porous structure as shown in Fig. 1a. The detailed process is summarized in Supplementary information. As shown in Fig. S1, a distinct porous structure in the designed film (P-ZnO) can be observed from optical microscope observation. To reveal the progress of porous structure of $\mathrm{P}-\mathrm{ZnO}$, the morphology features of pristine $\mathrm{ZnO}$ film, prepared $\mathrm{ZnO} / \mathrm{PEIE}$ composite film without washing, and $\mathrm{P}-\mathrm{ZnO}$ film were detected with the atomic force microscope (AFM) and scanning electron microscope (SEM) measurements as shown in Fig. 1b-g. The irregular morphology and the highest root-mean-squared surface

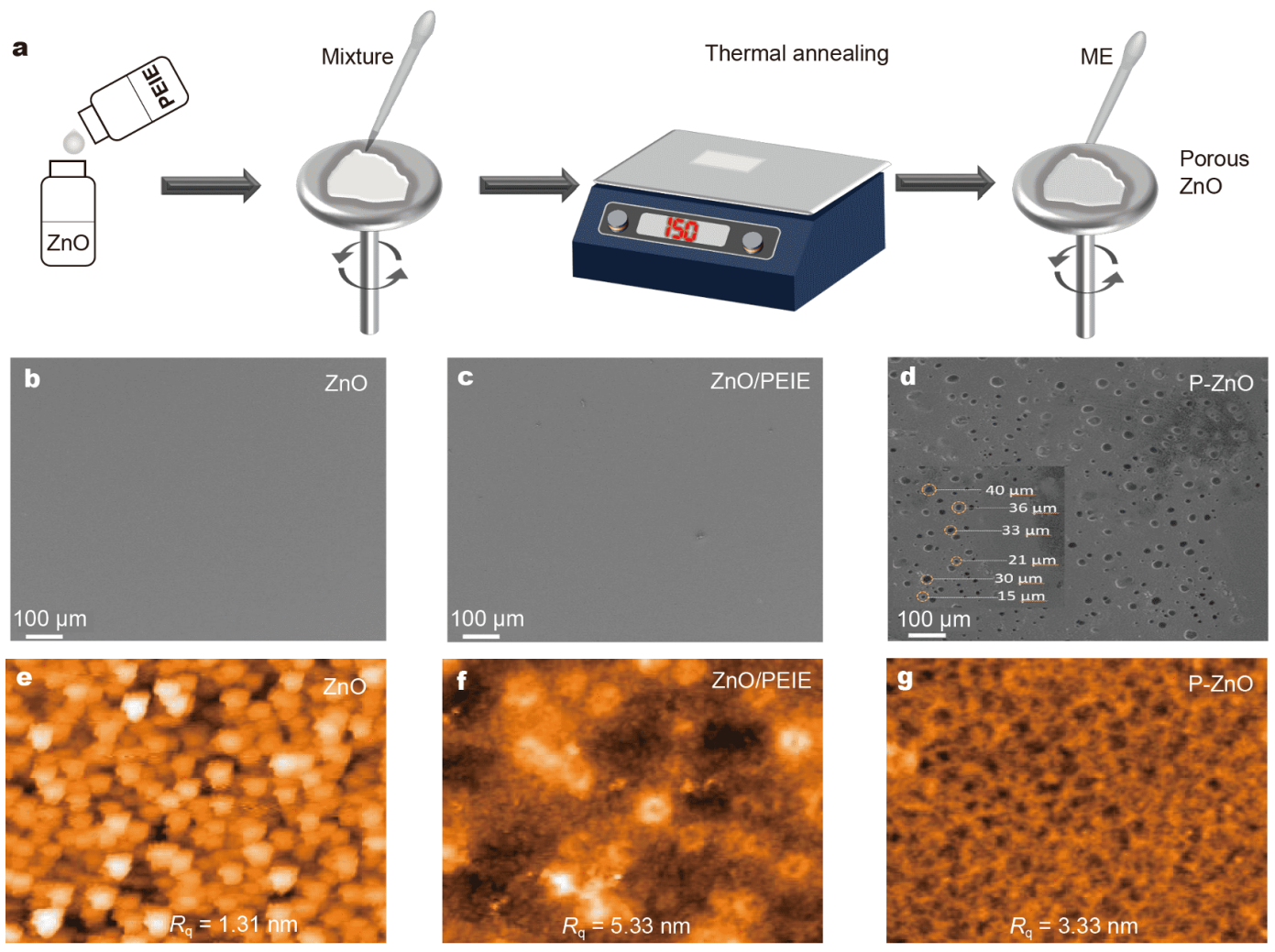

Figure 1 (a) The fabricating process of P-ZnO. SEM and AFM height images of (b, e) pristine ZnO film, (c, f) ZnO/PEIE composite film without solvent washing and $(\mathrm{d}, \mathrm{g}) \mathrm{P}-\mathrm{ZnO}$ film. 
roughness $\left(R_{\mathrm{q}}\right.$ of $\left.5.33 \mathrm{~nm}\right)$ of $\mathrm{ZnO} / \mathrm{PEIE}$ film may result from the aggregation of PEIE on the surface. After solvent washing, the $R_{\mathrm{q}}$ of $\mathrm{P}-\mathrm{ZnO}$ film shows a moderate value of $3.33 \mathrm{~nm}$ in the three films, which confirms the removal of PEIE component on the surface. Compared with the $R_{\mathrm{q}}$ value $(1.31 \mathrm{~nm})$ of pristine $\mathrm{ZnO}$ film, the proper increased surface roughness of $\mathrm{P}-\mathrm{ZnO}$ film may enhance the ohmic contact, which is beneficial to the charge transport and electron extraction. As shown in the Fig. 1d, the diameter scale of porous size in the cratered $\mathrm{P}-\mathrm{ZnO}$ film can be defined in $10-40 \mu \mathrm{m}$.

\section{XPS analysis}

In order to explore the composition of the derived films, XPS measurement was employed. Fig. 2 shows the narrow scans of $\mathrm{N} \mathrm{1s,} \mathrm{Zn} \mathrm{2p} \mathrm{and} \mathrm{O} \mathrm{1s} \mathrm{core} \mathrm{level} \mathrm{spectra} \mathrm{for} \mathrm{ZnO}$, $\mathrm{ZnO} / \mathrm{PEIE}$ and $\mathrm{P}-\mathrm{ZnO}$ films. It is evident that $\mathrm{N} 1$ s peak can be observed in the $\mathrm{P}-\mathrm{ZnO}$ film as shown in Fig. 2a, indicating the hybrid components of $\mathrm{P}-\mathrm{ZnO}$. The shifting binding energy of $\mathrm{N} 1 \mathrm{~s}$ core level from pure PEIE $(400.1 \mathrm{eV})$ to $\mathrm{P}-\mathrm{ZnO}(401.6 \mathrm{eV})$ implies that chemical bonding could occur between PEIE and $\mathrm{ZnO}$. The O 1s spectra were fitted with two Gaussian components as shown in Fig. 2b. The lower binding energy $(530 \mathrm{eV})$ can be assigned to the divalent oxygen $\left(\mathrm{O}^{2-}\right)$ state, while the higher binding energy $(532.5 \mathrm{eV})$ is related to the oxygendeficient regions from the hydroxyl bonds on the surface, indicating the intrinsic defects in the films. As shown in Fig. 2c, the $\mathrm{Zn} 2 \mathrm{p}$ peaks of $\mathrm{ZnO}$ and $\mathrm{P}-\mathrm{ZnO}$ are located at binding energies of 1044.4 and $1044.0 \mathrm{eV}$, respectively [47-49]. The lower binding energy of $\mathrm{Zn} 2 \mathrm{P}$ core level for $\mathrm{P}-\mathrm{ZnO}$ also implies that PEIE can effectively passivate the defects of $\mathrm{ZnO}$, which is favorable for the charge transport in P-ZnO-based devices.

\section{Miscibility and work function analysis}

The surface tensions and contact angles were measured to explore the miscibility of $\mathrm{P}-\mathrm{ZnO}$. As shown in Fig. 3a, the water contact angle is determined to be $36.0^{\circ}, 35.4^{\circ}, 27.5^{\circ}$ and $22.2^{\circ}$ for $\mathrm{ZnO}, \mathrm{P}-\mathrm{ZnO}, \mathrm{ZnO} / \mathrm{PEIE}$ and PEIE, respectively. The similar contact angles of $\mathrm{ZnO} / \mathrm{PEIE}$ and PEIE films confirm the above speculation that the aggregation of PEIE would occur on the surface during the fabricating process of $\mathrm{P}-\mathrm{ZnO}$ film. The nearly equal contact angles of pristine $\mathrm{ZnO}$ and $\mathrm{P}-\mathrm{ZnO}$ films suggest $\mathrm{ZnO}$ crystal is dominant on the surface of hybrid $\mathrm{P}-\mathrm{ZnO}$
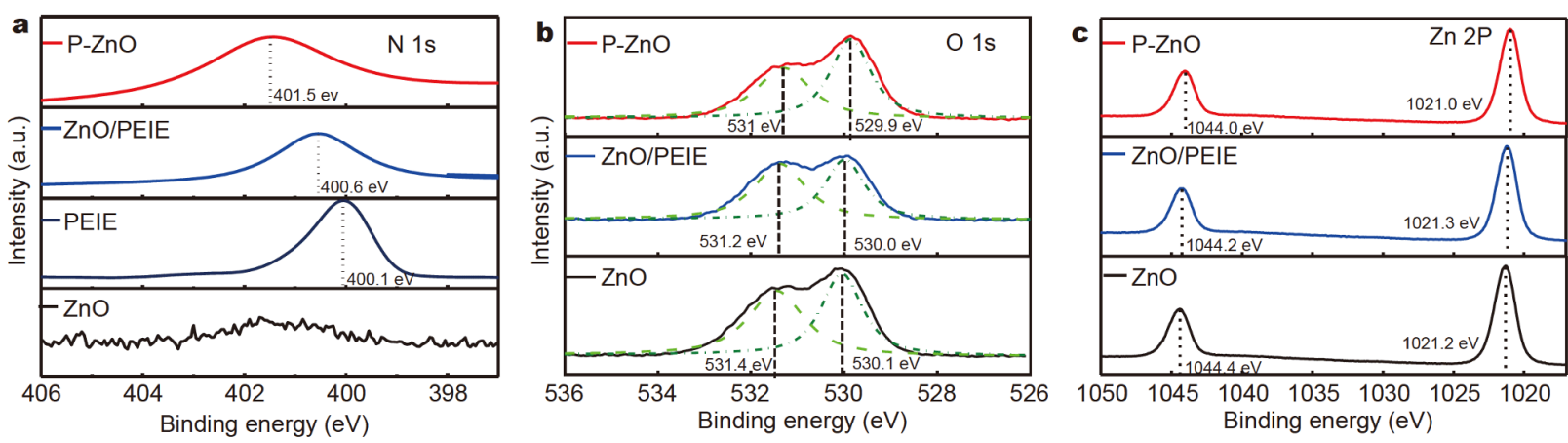

Figure 2 The high-resolution XPS spectra of (a) N 1s, (b) O 1s and (c) Zn 2P of pristine ZnO, PEIE, ZnO/PEIE and P-ZnO, respectively.
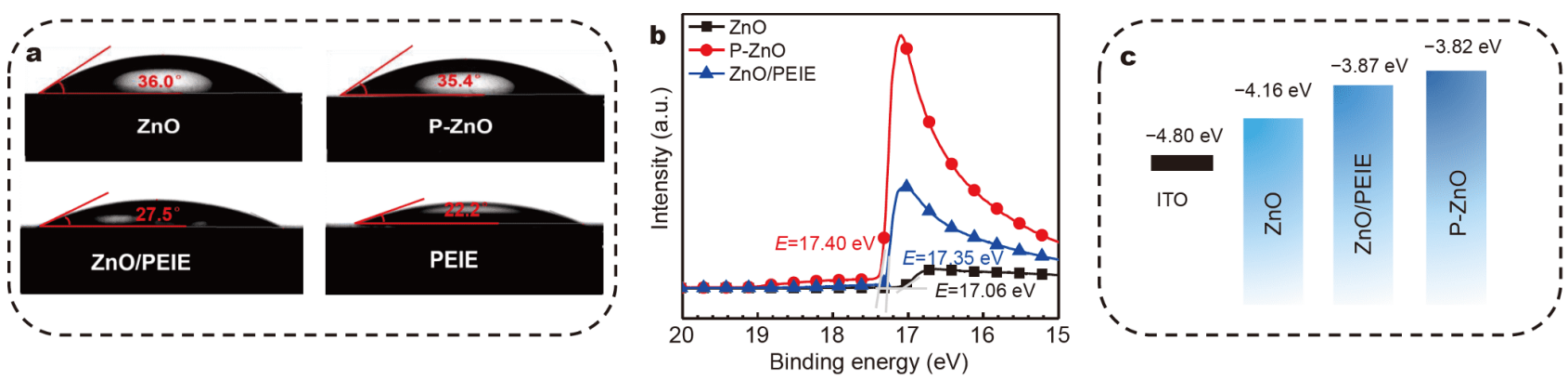

Figure 3 (a) Contact angle images on different ETLs. (b) UPS spectra and (c) the schematic energy diagrams of pristine $\mathrm{ZnO}, \mathrm{ZnO} / \mathrm{PEIE}$ and P-ZnO, respectively. 
film. To explore the distribution of PEIE in the P-ZnO film, the XPS behaviors with P-ZnO layer of varying thicknesses ( 5 and $45 \mathrm{~nm}$ ) were conducted as shown in Fig. S2. Clearly, $\mathrm{N} 1 \mathrm{~s}$ peak at $45 \mathrm{~nm}$ presents an enhanced intensity, and the $\mathrm{N}$ atomic proportion at $45 \mathrm{~nm}$ is also higher than that at $5 \mathrm{~nm}$. The results indicate that residual PEIE mainly exists at the bottom of P-ZnO which could prevent the direct contact between the active layer and ITO. The work function as the critical parameter of ETL was conducted with the UPS measurement. As shown in Fig. 3b, the binding energies of cut off region $\left(E_{\text {cutoff }}\right)$ for $\mathrm{ZnO}, \mathrm{ZnO} / \mathrm{PEIE}$ and $\mathrm{P}-\mathrm{ZnO}$ are $17.06,17.35$ and $17.40 \mathrm{eV}$, respectively. The work function value is calculated from the difference between $E_{\text {cutoff }}$ and the energy of $h v$, where $h v$ is the incident photon energy of $\mathrm{He}$ (I) source with a value of $21.22 \mathrm{eV}$. Consequently, the work functions of $\mathrm{ZnO}, \mathrm{ZnO} / \mathrm{PEIE}$ and $\mathrm{P}-\mathrm{ZnO}$ are 4.16, 3.87 and $3.82 \mathrm{eV}$, respectively. The schematic energy diagrams are summarized in Fig. 3c. The results indicate that besides a porous structure film formed in the hybrid $\mathrm{P}-\mathrm{ZnO}$, a reduced work function of $\mathrm{P}-\mathrm{ZnO}$ is also in- duced, which originates from the intrinsic molecular dipole of PEIE. It is beneficial to the charge transport and electron extraction in devices [50,51].

\section{Photovoltaic performance}

To explore the potential of P-ZnO serving as ETL, the photovoltaic performance of inverted OSCs was systematically investigated. The PBDB-T/DTPPSe-2F blend as shown in Fig. 4a was employed as the active layer, which was reported in our previous work [45]. As a comparison, the pristine $\mathrm{ZnO}$, PEIE and $\mathrm{ZnO} /$ PEIE-based devices were also fabricated. The detailed $J-V$ characteristics of OSCs are plotted in Fig. 4b and Fig. S3 and the related photovoltaic parameters are summarized in Table 1 and Tables S1-S3. The optimal condition for P-ZnO layer was found through tuning the concentration of prepared PEIE solution and volume ratio of $\mathrm{ZnO} / \mathrm{PEIE}$ solution $(0.5 \mathrm{wt} \%$, 2:1). The pristine $\mathrm{ZnO}$-based device presented a PCE of $13.65 \%$ with an open-circuit voltage $\left(V_{\mathrm{OC}}\right)$ of $0.84 \mathrm{~V}$, a $J_{\mathrm{SC}}$ of $22.03 \mathrm{~mA} \mathrm{~cm}^{-2}$ and a $\mathrm{FF}$ of $73.77 \%$. As shown in Fig. S3d, a decreased efficiency of $\mathrm{ZnO} /$ PEIE-based OSC
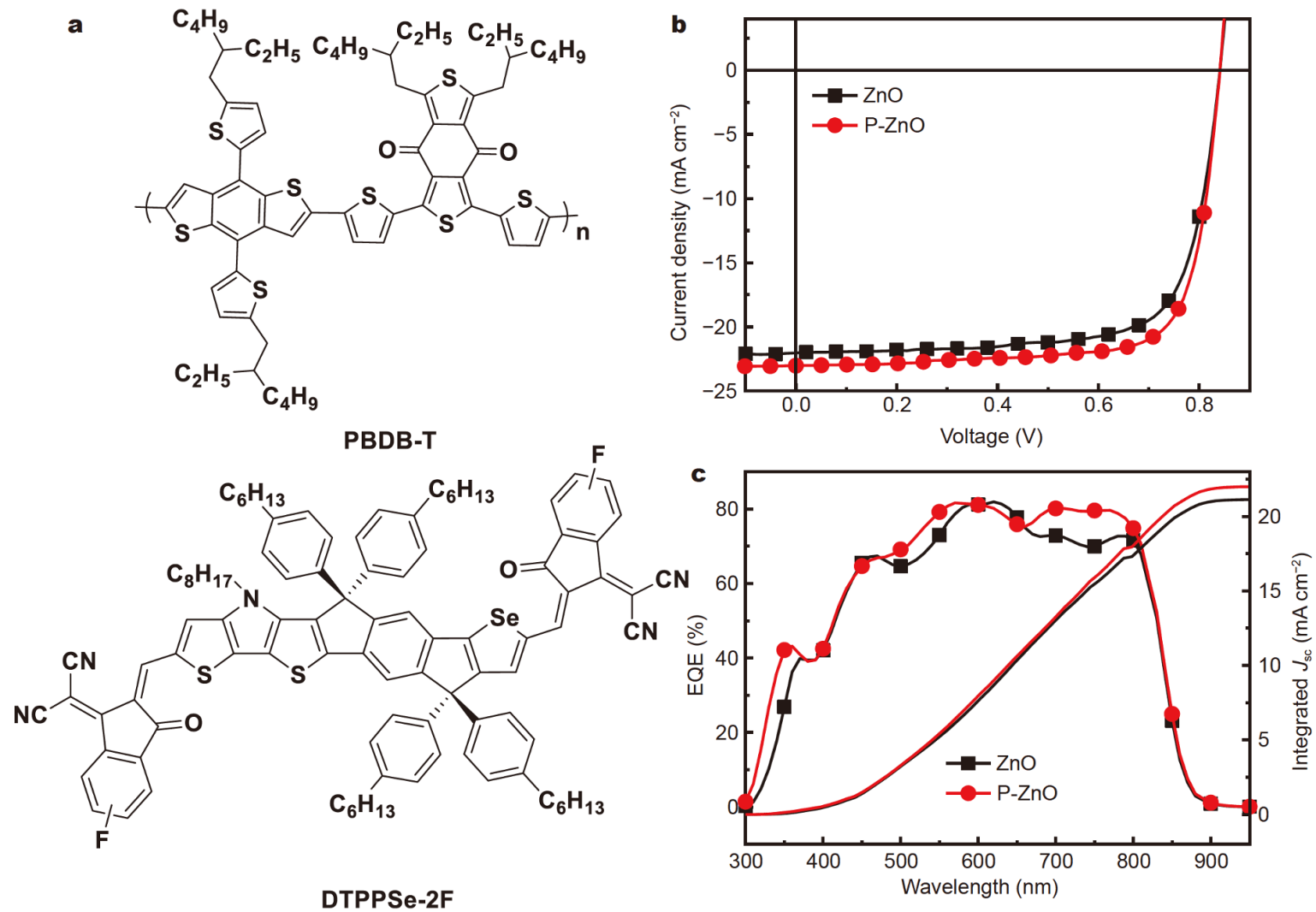

Figure 4 (a) The chemical structures of PBDB-T and DTPPSe-2F. (b) $J-V$ curves and (c) EQE curves of PBDB-T/DTPPSe-2F-based OSCs with different ETLs. 
Table 1 Photovoltaic parameters of OSCs with different ETLs

\begin{tabular}{|c|c|c|c|c|c|c|}
\hline Active layer & ETL & $V_{\mathrm{OC}}(\mathrm{V})$ & $J_{\mathrm{SC}}\left(\mathrm{mA} \mathrm{cm}^{-2}\right)$ & $J_{\mathrm{SC}, \mathrm{cal}}^{\mathrm{a}}\left(\mathrm{mA} \mathrm{cm}^{-2}\right)$ & FF (\%) & PCE (\%) \\
\hline \multirow{2}{*}{ PBDB-T/DTPPSe-2F } & $\mathrm{ZnO}$ & $0.84(0.84 \pm 0.00)$ & $22.03(21.92 \pm 0.12)$ & 21.18 & $73.77(73.57 \pm 0.16)$ & $13.65(13.50 \pm 0.15)$ \\
\hline & $\mathrm{P}-\mathrm{ZnO}$ & $0.84(0.83 \pm 0.01)$ & $22.96(22.87 \pm 0.06)$ & 22.21 & $76.62(76.15 \pm 0.53)$ & $14.78(14.56 \pm 0.23)$ \\
\hline \multirow{2}{*}{ PM6/Y6 } & $\mathrm{ZnO}$ & $0.85(0.85 \pm 0.00)$ & $24.93(24.82 \pm 0.12)$ & 24.07 & $72.57(71.93 \pm 0.61)$ & $15.38(15.22 \pm 0.15)$ \\
\hline & $\mathrm{P}-\mathrm{ZnO}$ & $0.85(0.85 \pm 0.00)$ & $25.70(25.52 \pm 0.13)$ & 24.80 & $75.84(75.37 \pm 0.42)$ & $16.57(16.42 \pm 0.13)$ \\
\hline \multirow{2}{*}{ PTB7-Th/PC ${ }_{71}$ BM } & $\mathrm{ZnO}$ & $0.80(0.80 \pm 0.00)$ & $16.70(16.35 \pm 0.19)$ & 15.54 & $68.32(67.27 \pm 0.18)$ & $9.12(8.91 \pm 0.25)$ \\
\hline & $\mathrm{P}-\mathrm{ZnO}$ & $0.80(0.80 \pm 0.00)$ & $17.26(17.07 \pm 0.13)$ & 16.22 & $71.31(70.98 \pm 0.42)$ & $9.85(9.72 \pm 0.13)$ \\
\hline
\end{tabular}

a) The values are integrated $J_{\mathrm{SC}}$ from EQE spectra. Optimal and statistical results are listed outside.

was revealed due to the simultaneously reduced $V_{\mathrm{OC}}, J_{\mathrm{SC}}$ and FF, which could be attributed to the poor charge mobility of PEIE. For the P-ZnO-based OSCs, a highest PCE of $14.78 \%$ was achieved with a slightly increased $J_{\mathrm{SC}}$ of $22.96 \mathrm{~mA} \mathrm{~cm}^{-2}$ and a notably improved $\mathrm{FF}$ of $76.62 \%$. To confirm the accuracy of $J-V$ measurements, the corresponding EQE curves of OSCs were tested as shown in Fig. 4c. The calculated values of $J_{\mathrm{SC}}$ are summarized in Table 1, which are matched well with the measured ones. It is worth noting that the P-ZnO-based device substantially exhibits a distinct enhanced response in the region of $450-800 \mathrm{~nm}$ as compared with the reference device, which directly induces the improved photocurrent. To further understand the improvement of photoresponse in the range of $450-800 \mathrm{~nm}$, optical simulations based on the transfer matrix formalism (TMF) method were performed. For a multilayered system, the energy distribution $(Q)$ of each layer is a function of wavelength $(\lambda)$ and position $(x)$, which can be calculated by Equation (1):

$Q(x, y)=0.5 \varepsilon_{0} c \alpha|E(x)|^{2}$,

where $c$ is the speed of light, $\varepsilon_{0}$ is the permittivity of vacuum, $\alpha$ is the absorption coefficient, and $|E(x)|$ is the optical electric field [49]. The two-dimensional (2D) color filled contour plots of the calculated squared optical electric field strength $|E(x)|^{2}$ distribution for the $\mathrm{ZnO}$ and $\mathrm{P}-\mathrm{ZnO}$-based devices are exhibited in Fig. 5a, b. Consequently, light intensity at $450-800 \mathrm{~nm}$ wavelength in the $\mathrm{P}-\mathrm{ZnO} / \mathrm{BHJ}$ layer is apparently higher than that of $\mathrm{ZnO} / \mathrm{BHJ}$ layer, which is in according with the EQE result [52-55]. The exciton generation rate within PBDB-T/ DTPPSe-2F film was calculated with different ETLs through optical simulations as shown in Figs S4, S5. Indeed, the exciton generation rate of $\mathrm{P}-\mathrm{ZnO} / \mathrm{PBDB}-\mathrm{T} /$ DTPPSe-2F film also presents an enhancement than that of $\mathrm{ZnO}$-based one. The enhanced photon harvesting in $\mathrm{P}$ $\mathrm{ZnO}$-based OSCs is ascribed to the porous structure which could soften reflection at the interface.

To analyze the accurate photon harvesting of OSCs, the absorption of active layer in the device was conducted to investigate the parasitic photon loss. The control devices were fabricated with poly(methyl methacrylate) (PMMA) instead of the PBDB-T/DTPPSe-2F blend for eliminating other effects [56]. The reflection spectra of all devices are shown in Fig. 5c. Clearly, the P-ZnO-based control device has a higher reflection than the $\mathrm{ZnO}$-based counterpart. Whereas, the P-ZnO-based OSC presents a lower reflection in the cell. These results manifest that enhanced light trapping can occur in the P-ZnO-based OSCs due to the unique porous structure. The calculated absorption and light harvesting efficiency of active layer in devices are shown in Fig. 5d, and the detailed calculation methods are summarized in the Supplementary information. It is evident that more incident photons can be absorbed by the PBDB-T/DTPPSe-2F blend when employing the P$\mathrm{ZnO}$ layer, which accounts for the increased $J_{\mathrm{SC}}$ in devices [57,58].

To analyze the variation of charge recombination properties in the derived devices, the dependences of $J_{\mathrm{SC}}$ and $V_{\mathrm{OC}}$ versus light intensity $\left(P_{\text {light }}\right)$ were studied. As shown in Fig. S3f, the $P_{\text {light }}$ dependence of $J_{\mathrm{SC}}$ is described as $J_{\mathrm{SC}} \propto P_{\text {light }}{ }^{\alpha}$, where the power-law exponent $\alpha$ reflects the bimolecular recombination behavior in device. The $\alpha$ values of $\mathrm{ZnO}$ - and $\mathrm{P}-\mathrm{ZnO}$-based devices are 0.96 and 0.99 , respectively, indicating the bimolecular recombination is effectively suppressed in the P-ZnO-based OSCs. Through analyzing the relationship between $V_{\mathrm{OC}}$ and $P_{\text {light }}$ in Fig. 5e, the slopes of $V_{\mathrm{OC}}$ versus $\ln \left(P_{\text {light }}\right)$ for $\mathrm{ZnO}$ - and $\mathrm{P}-\mathrm{ZnO}$-based devices are $1.32 \mathrm{kT} / \mathrm{q}$ and $1.12 \mathrm{kT} / \mathrm{q}$, respectively, where $k$ is the Boltzmann constant, $T$ is Kelvin temperature, and $q$ is the trap-assisted charge recombination which can be suppressed in the P-ZnObased OSCs. The charge collection and exciton dissociation can be investigated from the dependence of photogenerated current density $\left(J_{\mathrm{ph}}\right)$ on effective voltage $\left(V_{\text {eff }}\right)$. 

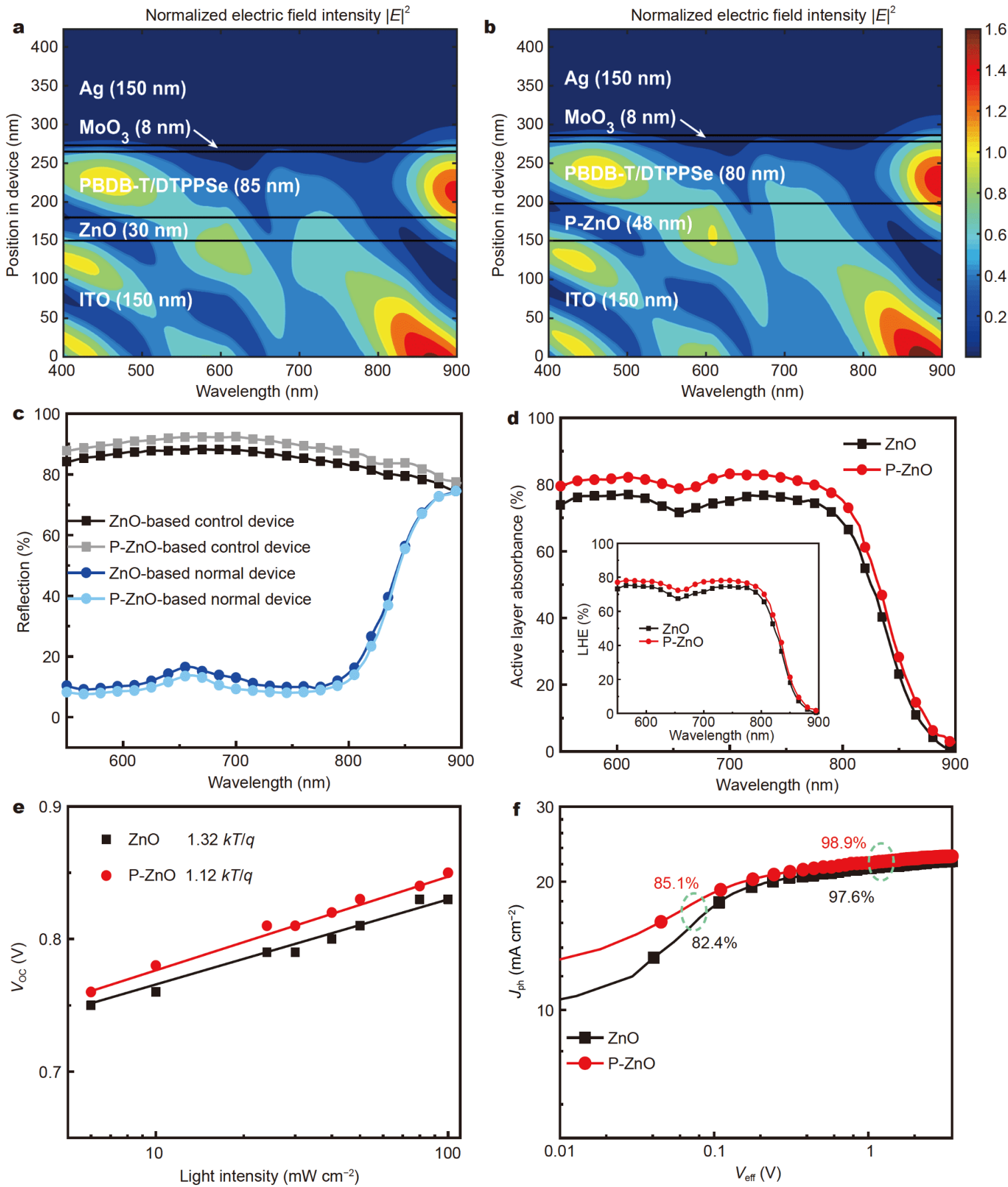

Figure 5 2D color filled contour plots of the normalized optical electric field $|E(x)|^{2}$ for (a) $\mathrm{ZnO}$ - and (b) P-ZnO-based devices, respectively. (c) Reflection spectra of normal and control devices. (d) Absorption spectra of active layers in cells. The reduced figure illustrates the light harvesting efficiency. (e) $V_{\mathrm{OC}}$ versus light intensity and (f) $J_{\mathrm{ph}}-V_{\text {eff }}$ characteristics for ZnO- and P-ZnO-based OSCs using PBDB-T/DTPPSe-2F as active layer.

The exciton dissociation and charge collection efficiency can be evaluated by the values of $J_{\mathrm{ph}} / J_{\mathrm{sat}}$ under shortcircuit current and maximal output conditions, where $J_{\text {sat }}$ is the saturation photocurrent [59-61]. Herein, the pseudo $J_{\text {sat }}$ values were selected at $2.1 \mathrm{~V}$ reverse bias for equitable comparison. As shown in Fig. $5 \mathrm{f}$, the $J_{\mathrm{ph}} / J_{\text {sat }}$ values under short-circuit current and maximal output conditions were calculated to be $97.6 \%$ and $82.4 \%$ for 
$\mathrm{ZnO}$-based device, $98.9 \%$ and $85.1 \%$ for P-ZnO-based device, respectively. The higher $J_{\mathrm{ph}} / J_{\text {sat }}$ values of P-ZnObased devices indicate more efficient exciton dissociation and charge collection, which can arouse the improved $J_{\mathrm{SC}}$ and FF.

\section{Long-term storage stability and generality of P-ZnO-based OSCs}

The long-term storage stability of PBDB-T/DTPPSe-2Fbased OSCs was also performed. The P-ZnO-based devices without encapsulation present enhanced storage stability whether in the $\mathrm{N}_{2}$ or ambient air condition, as shown in Fig. 6a, b and Figs S6, S7. The P-ZnO/PBDB-T/ DTPPSe-2F-based device can maintain its initial efficiency of $90 \%$ after $1000 \mathrm{~h}$ of storage in $\mathrm{N}_{2}$, while only $72 \%$ of its original PCE can be obtained for ZnO-based device. In the air condition, the $\mathrm{P}-\mathrm{ZnO}$-based device also reveals laudable storage stability, delivering a PCE of $12.41 \%$ (86\% of its original performance) after $1000 \mathrm{~h}$ aging. Inspired by the superior storage stability in ambient air, all air-processed OSCs were fabricated. The photovoltaic parameters are provided in Table S4, and the related $J-V$ and EQE curves are plotted in Fig. $6 c$, d. For the air-processed OSCs, the P-ZnO-based device also achieved an enhanced photoresponse and a higher PCE of $14.13 \%$ than that of $\mathrm{ZnO}$-based one (12.35\%). The promising PCE of $14.13 \%$ is among the highest efficiencies reported for air-processed OSCs in the literature as summarized in Tables S5, S6.

To explore the generality of P-ZnO serving as ETL for efficient OSCs, two frequently used BHJ systems (PM6/ $\mathrm{Y} 6$ and $\mathrm{PTB} 7-\mathrm{Th} / \mathrm{PC}_{71} \mathrm{BM}$ ) were utilized as shown in Fig. 7a. For an intuitional comparison, OSCs using $\mathrm{ZnO}$ as ETL were also carried out. As summarized in Fig. 7 and Table 1, the P-ZnO-based devices indeed present higher efficiencies compared with the counterparts. In the contrast, for the ZnO-based device, the PCEs of $15.38 \%$ and 9.12\% were achieved for PM6/Y6- and PTB7-Th/ $\mathrm{PC}_{71} \mathrm{BM}$-based OSCs, respectively, which are close to the reported value in the literatures [46,47]. Herein, the P$\mathrm{ZnO} / \mathrm{PM} 6 / \mathrm{Y} 6$-based device achieved an optimal PCE of $16.57 \%$ with simultaneously increased $J_{\mathrm{SC}}$ of $25.70 \mathrm{~mA} \mathrm{~cm}^{-2}$ and $\mathrm{FF}$ of $75.84 \%$. An enhancement of $8 \%$ in PCE (from $9.12 \%$ to $9.85 \%$ ) can also be achieved in the representative $\mathrm{PTB} 7-\mathrm{Th} / \mathrm{PC}_{71} \mathrm{BM}$-based OSCs with similar improvement. These results demonstrate the gen-
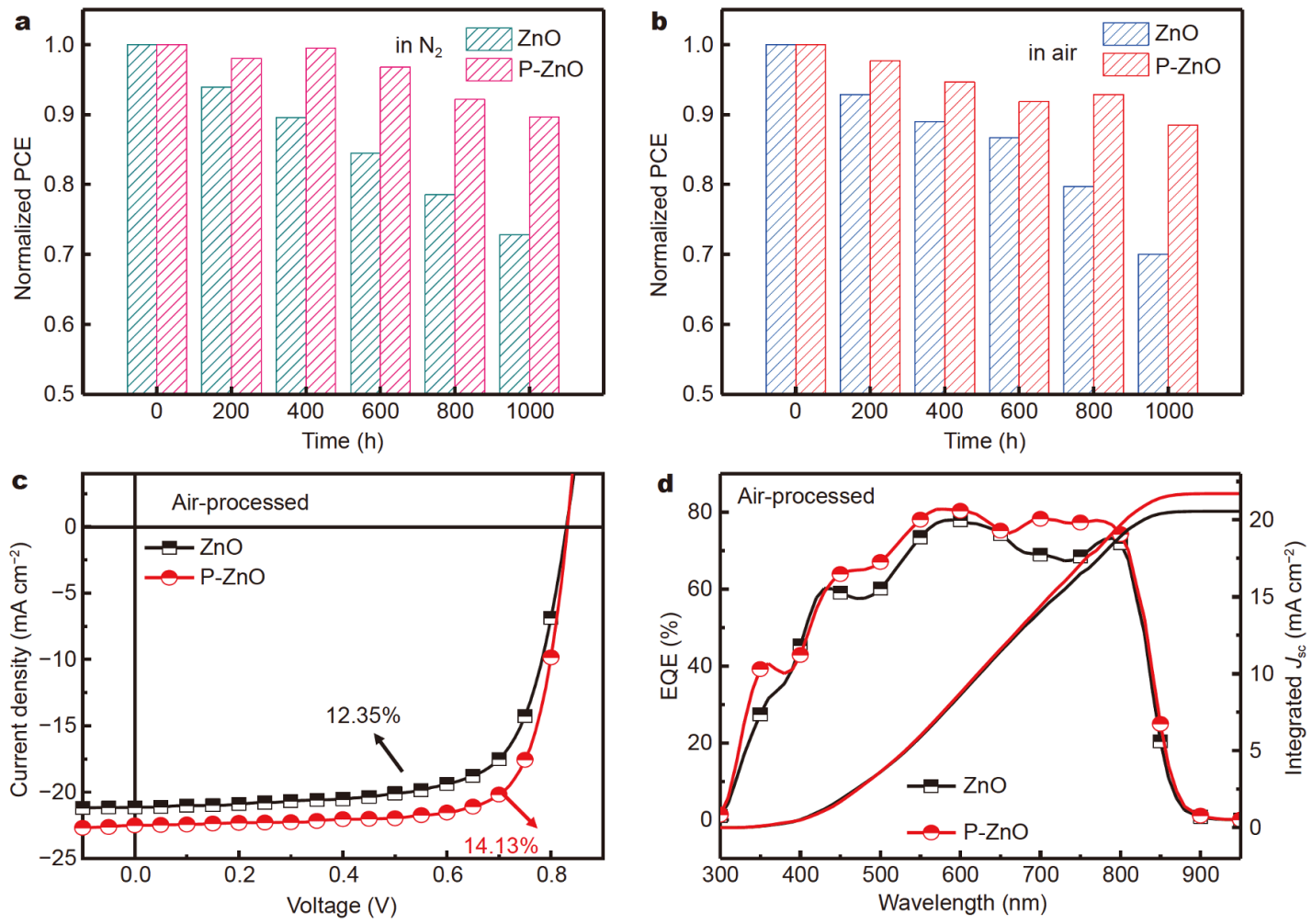

Figure 6 The variation of PCEs for ZnO- and P-ZnO-based OSCs using PBDB-T/DTPPSe-2F as active layer after aging in (a) $\mathrm{N}_{2}$ and (b) air. (c) $J$ - $V$ curves and (d) EQE curves of the air-processed OSCs using PBDB-T/DTPPSe-2F as active layer with different ETLs. 

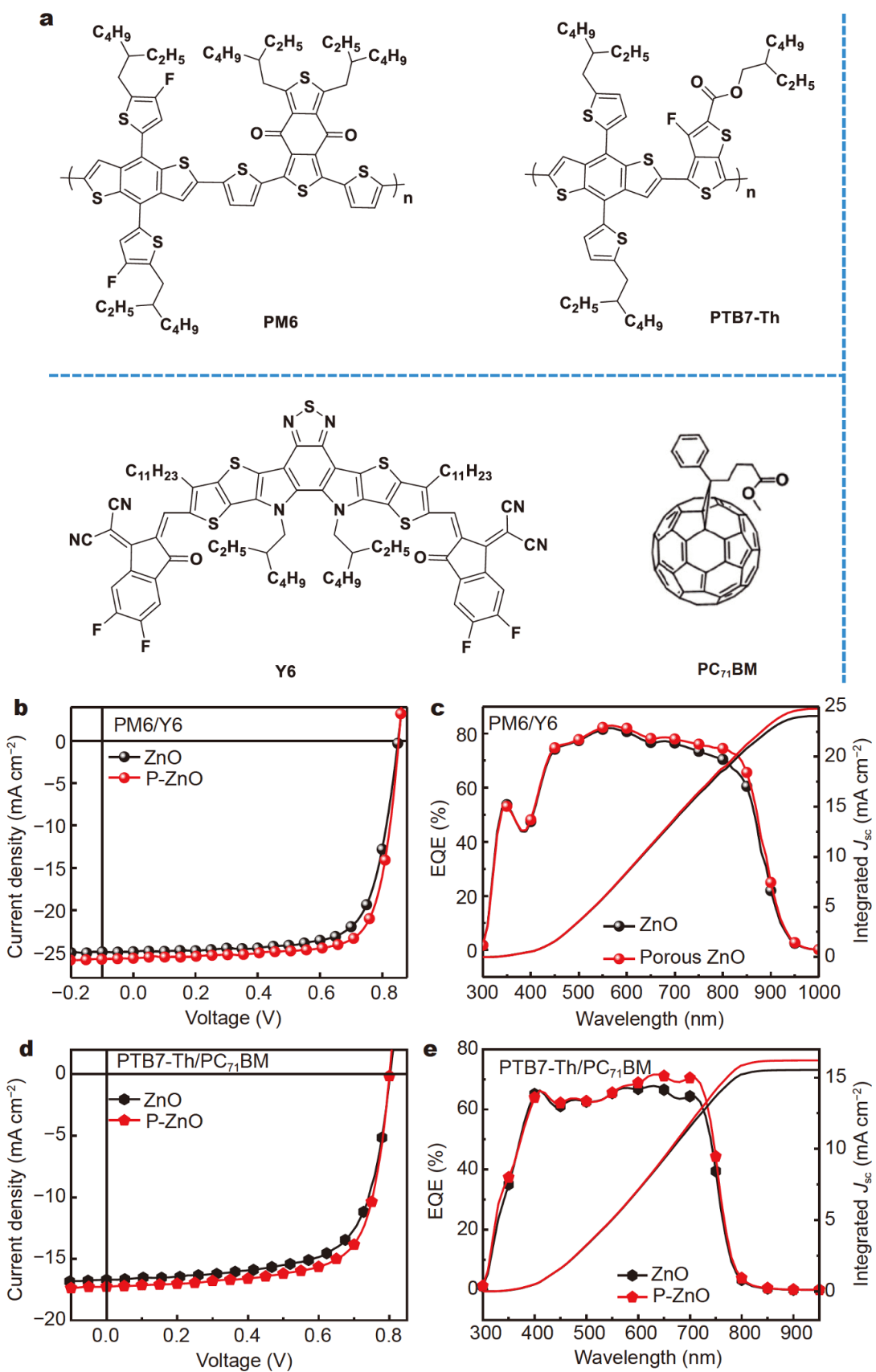

Figure 7 (a) The chemical structures of PM6, Y6, PTB7-Th and $\mathrm{PC}_{71} \mathrm{BM}$. (b) $J$ - $V$ curves and (c) EQE curves of PM6/Y6-based OSCs with different ETLs. (d) $J$ - $V$ curves and (e) EQE curves of PTB7-Th/PC ${ }_{71} \mathrm{BM}$-based OSCs with different ETLs, respectively.

erality of P-ZnO serving as ETL for efficient OSCs.

\section{CONCLUSION}

In summary, a porous inorganic/organic ( $\mathrm{ZnO} / \mathrm{PEIE})$ hybrid ETL, P-ZnO can be successfully adopted for efficient OSCs. The derived P-ZnO presents a unique porous surface feature with distinct distribution with residual
PEIE mainly at the bottom of ETL. And a reduced work function of $\mathrm{P}-\mathrm{ZnO}$ is induced, which is beneficial to the suppressed charge recombination and enhanced charge extraction in devices. P-ZnO-based OSCs also present an enhanced light trapping in the active layer compared with $\mathrm{ZnO}$-based counterparts. The increased light harvesting efficiency can account for the increased $J_{\mathrm{SC}}$. Conse- 
quently, the enhancements of $8 \%$ in PCEs have been achieved with enhanced $J_{\mathrm{SC}}$ and FF for P-ZnO-based OSCs, delivering higher PCEs of $14.78 \%, 9.85 \%$ and $16.57 \%$ for devices based on PBDB-T/DTPPSe-2F, PTB7$\mathrm{Th} / \mathrm{PC}_{71} \mathrm{BM}$ and $\mathrm{PM} 6 / \mathrm{Y} 6$, respectively. The $\mathrm{P}-\mathrm{ZnO} /$ PBDB-T/DTPPSe-2F-based OSCs without encapsulation also present improved long-term storage stability whether in the $\mathrm{N}_{2}$ or ambient air condition. Furthermore, the airprocessed OSCs based on P-ZnO/PBDB-T/DTPPSe-2F possess a promising PCE of $14.13 \%$, which is among the highest efficiencies reported for air-processed OSCs in the literature. These results demonstrate the great potential of the porous hybrid $\mathrm{P}-\mathrm{ZnO}$ as ETL for constructing highperformance and air-stable OSCs.

\section{Received 20 July 2020; accepted 26 August 2020;} published online 15 December 2020

1 Song Y, Zhang K, Dong S, et al. Semitransparent organic solar cells enabled by a sequentially deposited bilayer structure. ACS Appl Mater Interfaces, 2020, 12: 18473-18481

2 Qin J, An C, Zhang J, et al. 15.3\% Efficiency all-small-molecule organic solar cells enabled by symmetric phenyl substitution. Sci China Mater, 2020, 63: 1142-1150

3 Wang $\mathrm{H}$, Cao J, Yu J, et al. Molecular engineering of central fusedring cores of non-fullerene acceptors for high-efficiency organic solar cells. J Mater Chem A, 2019, 7: 4313-4333

4 Yan C, Barlow S, Wang Z, et al. Non-fullerene acceptors for organic solar cells. Nat Rev Mater, 2018, 3: 18003

5 Hou J, Inganäs O, Friend RH, et al. Organic solar cells based on non-fullerene acceptors. Nat Mater, 2018, 17: 119-128

6 Liu Q, Jiang Y, Jin K, et al. 18\% Efficiency organic solar cells. Sci Bull, 2020, 65: 272-275

7 An Q, Wang J, Gao W, et al. Alloy-like ternary polymer solar cells with over 17.2\% efficiency. Sci Bull, 2020, 65: 538-545

8 Zhan L, Li S, Lau TK, et al. Over 17\% efficiency ternary organic solar cells enabled by two non-fullerene acceptors working in an alloy-like model. Energy Environ Sci, 2020, 13: 635-645

9 Cui Y, Yao H, Zhang J, et al. Single-junction organic photovoltaic cells with approaching 18\% efficiency. Adv Mater, 2020, 32: 1908205

10 Yue Q, Wu H, Zhou Z, et al. 13.7\% Efficiency small-molecule solar cells enabled by a combination of material and morphology optimization. Adv Mater, 2019, 31: 1904283

11 Jia T, Zhang J, Zhong W, et al. 14.4\% Efficiency all-polymer solar cell with broad absorption and low energy loss enabled by a novel polymer acceptor. Nano Energy, 2020, 72: 104718

12 Qiu B, Chen Z, Qin S, et al. Highly efficient all-small-molecule organic solar cells with appropriate active layer morphology by side chain engineering of donor molecules and thermal annealing. Adv Mater, 2020, 32: 1908373

13 Wan J, Zhang L, He Q, et al. High-performance pseudoplanar heterojunction ternary organic solar cells with nonfullerene alloyed acceptor. Adv Funct Mater, 2020, 30: 1909760

14 Sun $\mathrm{H}$, Liu $\mathrm{T}, \mathrm{Yu}$ J, et al. A monothiophene unit incorporating both fluoro and ester substitution enabling high-performance donor polymers for non-fullerene solar cells with $16.4 \%$ efficiency.
Energy Environ Sci, 2019, 12: 3328-3337

15 Wang $\mathrm{H}$, Zhang Z, Yu J, et al. Nonacyclic carbazole-based nonfullerene acceptors enable over $12 \%$ efficiency with enhanced stability for organic solar cells. J Mater Chem A, 2019, 7: 21903-21910

16 Wang Y, Wang Y, Zhu L, et al. A novel wide-bandgap small molecule donor for high efficiency all-small-molecule organic solar cells with small non-radiative energy losses. Energy Environ Sci, 2020, 13: 1309-1317

17 Cui Y, Yao H, Zhang J, et al. Over 16\% efficiency organic photovoltaic cells enabled by a chlorinated acceptor with increased opencircuit voltages. Nat Commun, 2019, 10: 2515

$18 \mathrm{Xu} \mathrm{C}$, Wang J, An Q, et al. Ternary small molecules organic photovoltaics exhibiting $12.84 \%$ efficiency. Nano Energy, 2019, 66: 104119

19 Wang $\mathrm{H}$, Zhang Z, Yu J, et al. Over $15 \%$ efficiency in ternary organic solar cells by enhanced charge transport and reduced energy loss. ACS Appl Mater Interfaces, 2020, 12: 21633-21640

20 Zhu L, Zhong W, Qiu C, et al. Aggregation-induced multilength scaled morphology enabling $11.76 \%$ efficiency in all-polymer solar cells using printing fabrication. Adv Mater, 2019, 31: 1902899

21 Zhu L, Zhang M, Zhou G, et al. Efficient organic solar cell with $16.88 \%$ efficiency enabled by refined acceptor crystallization and morphology with improved charge transfer and transport properties. Adv Energy Mater, 2020, 10: 1904234

22 Ma X, Wang J, An Q, et al. Highly efficient quaternary organic photovoltaics by optimizing photogenerated exciton distribution and active layer morphology. Nano Energy, 2020, 70: 104496

23 Gao K, Jo SB, Shi X, et al. Over 12\% efficiency nonfullerene allsmall-molecule organic solar cells with sequentially evolved multilength scale morphologies. Adv Mater, 2019, 31: 1807842

24 Wang C, Moro F, Ni S, et al. Thermal-annealing effects on energy level alignment at organic heterojunctions and corresponding voltage losses in all-polymer solar cells. Nano Energy, 2020, 72: 104677

25 Liang X, Bai S, Wang X, et al. Colloidal metal oxide nanocrystals as charge transporting layers for solution-processed light-emitting diodes and solar cells. Chem Soc Rev, 2017, 46: 1730-1759

26 Li X, Zhang W, Usman $\mathrm{K}$, et al. Small molecule interlayers in organic solar cells. Adv Energy Mater, 2018, 8: 1702730

27 Huang Z, Ouyang D, Shih CJ, et al. Solution-processed ternary oxides as carrier transport/injection layers in optoelectronics. Adv Energy Mater, 2020, 10: 1900903

28 Oh H, Krantz J, Litzov I, et al. Comparison of various sol-gel derived metal oxide layers for inverted organic solar cells. Sol Energy Mater Sol Cells, 2011, 95: 2194-2199

29 Richardson BJ, Wang X, Almutairi A, et al. High efficiency PTB7based inverted organic photovoltaics on nano-ridged and planar zinc oxide electron transport layers. J Mater Chem A, 2015, 3: 5563-5571

30 Ma H, Yip HL, Huang F, et al. Interface engineering for organic electronics. Adv Funct Mater, 2010, 20: 1371-1388

31 Zhang D, Choy WCH, Xie F, et al. Plasmonic electrically functionalized $\mathrm{TiO}_{2}$ for high-performance organic solar cells. Adv Funct Mater, 2013, 23: 4255-4261

32 MacLeod BA, Tremolet de Villers BJ, Schulz P, et al. Stability of inverted organic solar cells with $\mathrm{ZnO}$ contact layers deposited from precursor solutions. Energy Environ Sci, 2015, 8: 592-601

33 Sun Y, Seo JH, Takacs CJ, et al. Inverted polymer solar cells integrated with a low-temperature-annealed sol-gel-derived $\mathrm{ZnO}$ film as an electron transport layer. Adv Mater, 2011, 23: 1679-1683 
34 Jin WY, Ginting RT, Jin SH, et al. Highly stable and efficient inverted organic solar cells based on low-temperature solutionprocessed PEIE and ZnO bilayers. J Mater Chem A, 2016, 4: 37843791

35 Li Z, Chueh CC, Jen AKY. Recent advances in molecular design of functional conjugated polymers for high-performance polymer solar cells. Prog Polym Sci, 2019, 99: 101175

36 Lin PC, Wong YT, Su YA, et al. Interlayer modification using ecofriendly glucose-based natural polymers in polymer solar cells. ACS Sustain Chem Eng, 2018, 6: 14621-14630

37 Pan F, Sun C, Li Y, et al. Solution-processable N-doped graphenecontaining cathode interfacial materials for high-performance organic solar cells. Energy Environ Sci, 2019, 12: 3400-3411

38 Zhang K, Xia R, Fan B, et al. 11.2\% all-polymer tandem solar cells with simultaneously improved efficiency and stability. Adv Mater, 2018, 30: 1803166

39 Lee BH, Jung IH, Woo HY, et al. Multi-charged conjugated polyelectrolytes as a versatile work function modifier for organic electronic devices. Adv Funct Mater, 2014, 24: 1100-1108

40 He Z, Xiao B, Liu F, et al. Single-junction polymer solar cells with high efficiency and photovoltage. Nat Photon, 2015, 9: 174-179

41 Zhou Y, Fuentes-Hernandez C, Shim J, et al. A universal method to produce low-work function electrodes for organic electronics. Science, 2012, 336: 327-332

42 Goo JS, Shin SC, You YJ, et al. Polymer surface modification to optimize inverted organic photovoltaic devices under indoor light conditions. Sol Energy Mater Sol Cells, 2018, 184: 31-37

43 Li P, Wang G, Cai L, et al. High-efficiency inverted polymer solar cells controlled by the thickness of polyethylenimine ethoxylated (PEIE) interfacial layers. Phys Chem Chem Phys, 2014, 16: $23792-$ 23799

44 Cao J, Qu S, Yu J, et al. 13.76\% efficiency nonfullerene solar cells enabled by selenophene integrated dithieno[3,2-b:2',3'-d]pyrrole asymmetric acceptors. Mater Chem Front, 2020, 4: 924-932

45 Yuan J, Zhang Y, Zhou L, et al. Single-junction organic solar cell with over $15 \%$ efficiency using fused-ring acceptor with electrondeficient core. Joule, 2019, 3: 1140-1151

46 Park S, Cha MJ, Seo JH, et al. Treating the poly(3,4-ethylenedioxythiophene):poly(styrenesulfonate) surface with hydroquinone enhances the performance of polymer solar cells. ACS Appl Mater Interfaces, 2018, 10: 41578-41585

47 Yan Y, Li W, Cai J, et al. Improved efficiency in fullerene and nonfullerene polymer solar cells having an interdigitated interface with the electron transport layer. Mater Chem Front, 2018, 2: 1859-1865

48 Wang C, Li C, MacKenzie RCI, et al. Polyelectrolyte interlayers with a broad processing window for high efficiency inverted organic solar cells towards mass production. J Mater Chem A, 2018, 6: $17662-17670$

49 Zhang Z, Zhang Z, Zhao B, et al. Polymer with a 3D conductive network: A thickness-insensitive electron transport layer for inverted polymer solar cells. J Mater Chem A, 2018, 6: 12969-12973

50 Sun R, Deng D, Guo J, et al. Spontaneous open-circuit voltage gain of fully fabricated organic solar cells caused by elimination of interfacial energy disorder. Energy Environ Sci, 2019, 12: 2518-2528
51 Woo S, Hyun Kim W, Kim H, et al. 8.9\% Single-stack inverted polymer solar cells with electron-rich polymer nanolayer-modified inorganic electron-collecting buffer layers. Adv Energy Mater, 2014, 4: 1301692

52 Zou J, Yip HL, Zhang Y, et al. High-performance inverted polymer solar cells: Device characterization, optical modeling, and holetransporting modifications. Adv Funct Mater, 2012, 22: 2804-2811

53 Wang F, Wang Y, Liu H, et al. Fine tuning the light distribution within the photoactive layer by both solution-processed anode and cathode interlayers for high performance polymer solar cells. Sol RRL, 2018, 2: 1800141

54 Chen KS, Salinas JF, Yip HL, et al. Semi-transparent polymer solar cells with $6 \%$ PCE, $25 \%$ average visible transmittance and a color rendering index close to 100 for power generating window applications. Energy Environ Sci, 2012, 5: 9551

55 Chueh CC, Chien SC, Yip HL, et al. Toward high-performance semi-transparent polymer solar cells: Optimization of ultra-thin light absorbing layer and transparent cathode architecture. Adv Energy Mater, 2013, 3: 417-423

$56 \mathrm{Hu} \mathrm{Z}$, Yang L, Gao W, et al. Over $15.7 \%$ efficiency of ternary organic solar cells by employing two compatible acceptors with similar LUMO levels. Small, 2020, 16: 2000441

57 Huyen Nguyen TM, Bark CW. Highly porous nanostructured $\mathrm{NiO} @ \mathrm{C}$ as interface-effective layer in planar n-i-p perovskite solar cells. J Alloys Compd, 2020, 841: 155711

58 Agrios AG, Hagfeldt A. Low-temperature $\mathrm{TiO}_{2}$ films for dye-sensitized solar cells: Factors affecting energy conversion efficiency. J Phys Chem C, 2008, 112: 10021-10026

59 Wang J, Zheng Z, Zhang D, et al. Regulating bulk-heterojunction molecular orientations through surface free energy control of holetransporting layers for high-performance organic solar cells. Adv Mater, 2019, 31: 1806921

60 Yang B, Zhang S, Li S, et al. A self-organized poly(vinylpyrrolidone)-based cathode interlayer in inverted fullerene-free organic solar cells. Adv Mater, 2019, 31: 1804657

61 Zheng Z, Hu Q, Zhang S, et al. A highly efficient non-fullerene organic solar cell with a fill factor over 0.80 enabled by a fine-tuned hole-transporting layer. Adv Mater, 2018, 30: 1801801

Acknowledgements This work was supported by the National Natural Science Foundation of China (21905137) and the Natural Science Foundation of Jiangsu Province (BK20180496).

Author contributions $\mathrm{Yu} \mathrm{J}$ and Qu S conceived and designed the experiments; Cao J provided the acceptor DTPPSe-2F; Wang $\mathrm{H}$ and Guang S performed the morphology characterizations; Liu X performed the optical simulations; Yu J and Tang W directed the project. All authors contributed to the general discussion.

Conflict of interest The authors declare that they have no conflict of interest.

Supplementary information online version of the paper.
Supporting data are available in the 


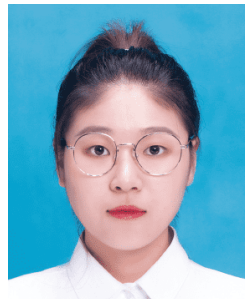

Shenya Qu received her BSc degree from Nanjing Forest University. She has been pursuing her postgraduate degree in Nanjing University of Science and Technology since 2018. Her research interests focus on the device fabrication and optical optimization for interlayer modification in organic solar cells.

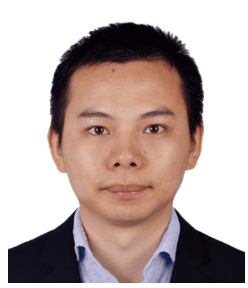

Jiangsheng Yu received his $\mathrm{PhD}$ degree in 2017 from Nanjing University of Science and Technology and the University of Washington. Then, he joined MIIT Key Laboratory of Advanced Solid Laser in Nanjing University of Science and Technology. His research mainly focuses on photovoltaic material development and device engineering on organic solar cells.

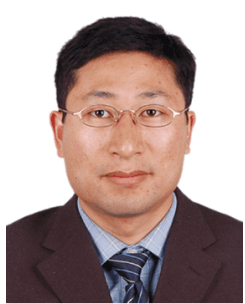

Weihua Tang has been a professor in Nanjing University of Science and Technology since 2009. $\mathrm{He}$ received his $\mathrm{PhD}$ degree in chemistry from National University of Singapore. His research interests mainly focus on molecular design of conjugated materials and device optimization for organic/perovskite solar cells and energy storage systems.
一种可增强光陷阱效应的多孔 ZnO/PEIE电子传 输层在高效有机太阳能电池中的应用

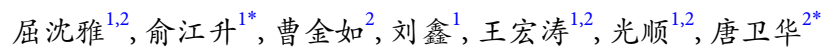

摘要 在本工作中, 我们制备了一种多孔的有机/无机复合电子传 输层 $(\mathrm{P}-\mathrm{ZnO})$, 并将其成功用于反向有机太阳能电池中. $\mathrm{P}-\mathrm{ZnO}$ 不 仅拥有适宜的功函, 且可形成较大欧姆接触面积的独特表面, 有利 于器件中的电荷提取. 与 $\mathrm{ZnO}$ 基器件相比, $\mathrm{P}-\mathrm{ZnO}$ 基器件的活性层 具有增强的光陷阴效应. 在PBDB-T/DTPPSe-2F, PM6/Y6和PTB7$\mathrm{Th} / \mathrm{PC}_{71} \mathrm{BM}$ 三个活性层体系中, 基于 $\mathrm{P}-\mathrm{ZnO}$ 的器件都可实现 $8 \%$ 增 幅的效率提升. 尤其是P-ZnO/PBDB-T/DTPPSe-2F的未封装器件 无论在氮气还是空气氛围下, 均表现出良好的长期稳定性. 在空气 中制备的P-ZnO/PBDB-T/DTPPSe-2F器件仍可实现 $14.13 \%$ 的高效 率, 这是目前文献报道的空气氛围制备有机太阳能电池的最高效 率之一. 实验结果表明, $\mathrm{P}-\mathrm{ZnO}$ 作为电子传输层在构建高性能和空 气稳定的有机太阳能电池方面具有巨大的应用潜力. 